Article

\title{
Morphology evolution of acetic acid-modulated MIL-53(Fe) for efficient selective oxidation of $\mathrm{H}_{2} \mathrm{~S}$
}

\author{
Xiaoxiao Zheng, Sihui Qi, Yanning Cao, Lijuan Shen *, Chaktong Au, Lilong Jiang \# \\ National Engineering Research Center of Chemical Fertilizer Catalyst, Fuzhou University, Fuzhou 350002, Fujian, China
}

\section{A R T I C L E I N F O}

\section{Article history:}

Received 27 March 2020

Accepted 11 May 2020

Published 5 February 2021

\section{Keywords:}

Fe-metal-organic frameworks

Hydrogen sulfide

Selective oxidation

Controllable synthesis

Acetic acid

Modulation

\begin{abstract}
A B S T R A C T
MIL-53(Fe) was synthesized using a "modulator approach" that utilizes acetic acid (HAc) as an additive to control the size and morphology of the resulting crystals. We demonstrate that after activation under vaccum at $100{ }^{\circ} \mathrm{C}$, the MIL-53(Fe) functions well for $\mathrm{H}_{2} \mathrm{~S}$ selective oxidation. The introduction of acetic acid in the presence of benzene-1,4-dicarboxylic acid ( $\left.\mathrm{H}_{2} \mathrm{BDC}\right)$ would result in a series of MIL-53(Fe) nanocrystals (denoted as MIL-53(Fe)- $x \mathrm{H}, x$ stands for the volume of added HAc with morphology evoluting from irregular particles to short hexagonal columns. The vacuum treatment facilitates the removal of acetate groups, thus generating $\mathrm{Fe}^{3+}$ Lewis acid sites. Consequently, the resulted MIL-53(Fe)- $x \mathrm{H}$ exhibits good catalytic activity $\left(98 \% \mathrm{H}_{2} \mathrm{~S}\right.$ conversion and $92 \%$ sulfur selectivity ) at moderate reaction temperatures $\left(100-190{ }^{\circ} \mathrm{C}\right)$. The MIL-53(Fe)-5H is superior to the traditional iron-based catalysts, showing stable performance in a test period of $55 \mathrm{~h}$. (C) 2021, Dalian Institute of Chemical Physics, Chinese Academy of Sciences. Published by Elsevier B.V. All rights reserved.
\end{abstract}

\section{Introduction}

Hydrogen sulfide $\left(\mathrm{H}_{2} \mathrm{~S}\right)$, originating from industrial processes such as coal gasification and oil refining, is one of the most malodorous and toxic gases [1-3]. The gas is not only corrosive to metals pipelines, but also hazardous to health and harmful to the environment $[4,5]$. It is hence imperative to control the emission of $\mathrm{H}_{2} \mathrm{~S}$. Among the various established technologies for $\mathrm{H}_{2} \mathrm{~S}$ removal, the catalytic selective oxidation of $\mathrm{H}_{2} \mathrm{~S}$ to useful sulfur looks promising. It is a green process and the capital requirement is low [6,7]. In addition, thermodynamically it is possible to achieve complete conversion of $\mathrm{H}_{2} \mathrm{~S}$ to sulfur: $\mathrm{H}_{2} \mathrm{~S}+(1 / 2) \mathrm{O}_{2} \rightarrow(1 / n) \mathrm{S}_{n}+\mathrm{H}_{2} \mathrm{O}$ [8]. Nonetheless, the essential task for reaching practical application is the development of efficient and stable catalysts.

Being cheap and relatively high in activity, iron oxides have been intensely studied for $\mathrm{H}_{2} \mathrm{~S}$ selective oxidation [9]. However, for this class of catalysts, the use of excess oxygen is required and the sulfur selectivity is usually low. With the significant generation of $\mathrm{SO}_{2}$ as a result of $\mathrm{H}_{2} \mathrm{~S}$ deep oxidation, the sulfur yield is poor [10]. Furthermore, catalyst deactivation is common due to surface sulfidation and sulfur deposition [11]. With the goal of achieving practical application, researchers have put in tremendous efforts to modify iron oxides, in particular by metal doping (e.g., Ce, $\mathrm{Cr}, \mathrm{V}$ ) and fabrication of support materials (e.g., Fe/ $\beta$-SiC and Fe/PILC) [12-14]. However, the systems are energy consuming because the reaction temperature is relatively high $\left(\geq 250{ }^{\circ} \mathrm{C}\right)$. Moreover, the poor dispersion and large particle size of iron species is always a concern. Also, to design a proper support for iron catalysts is a complicate issue because a support may react with $\mathrm{H}_{2} \mathrm{~S}$ or products to form sulfate, resulting in catalyst deactivation [15]. It still remains a

\footnotetext{
* Corresponding author. Tel: +86-591-83731234; E-mail: syhgslj@fzu.edu.cn

\# Corresponding author. Tel: +86-591-83731234; E-mail: jll@fzu.edu.cn

This work was supported by the National Science Fund for Distinguished Young Scholars of China (21825801), the National Natural Science Foundation of China (21603034), and the Natural Science Foundation of Fujian Province (2017J05022).

DOI: 10.1016/S1872-2067(20)63625-7 | http://www.sciencedirect.com/science/journal/18722067 | Chin. J. Catal., Vol. 42 , No. 2, February 2021
} 
grand challenge to develop iron catalysts that can perform acceptably well in the selective oxidation of $\mathrm{H}_{2} \mathrm{~S}$ at temperatures below $200{ }^{\circ} \mathrm{C}$.

Emerging as a new class of porous material, metal-organic frameworks (MOFs) have triggered keen research interest owing to their unique properties and functionalities. The advantages of deploying MOFs in heterogeneous catalysis have been highlighted in recent publications [16-23]. For example, (i) the metal content of MOFs is high, and the metal atoms are maximally dispersed with the open metal centers functioning as active sites for catalytic action; (ii) the ultrahigh specific surface area and regular pore structure of MOFs enables better contact between reactants and active sites; and (iii) the structural flexibility and tunability of MOFs provides a versatile knob for functionality adjustment to meet specific catalytic needs. For these reasons, it is envisaged that MOFs could be utilized for selective oxidation of $\mathrm{H}_{2} \mathrm{~S}$ to sulfur.

The application of MOFs for desulfurization is still in its infancy. Herein, we report the preparation of MIL-53(Fe) using a modulation approach. MIL-53(Fe) (Fe(OH)BDC $x \mathrm{H}_{2} \mathrm{BDC}$ ) was chosen as candidate for our study because of cost and stability concerns. The resulted catalyst shows outstanding performance for the selective conversion of $\mathrm{H}_{2} \mathrm{~S}$. It was synthesized via a modified solvothermal method. To control the size and morphology of the resulting crystals, acetic acid (HAc) was added as capping agent to modulate the coordination between metal ions and organic linkers. The outcome is rate regulation of framework extension and crystal growth, and a series of MIL-53(Fe) particles with morphology ranging from bulky irregular shapes to highly uniform short columns was obtained. The optimized MIL-53(Fe) is highly stable, showing $\mathrm{H}_{2} \mathrm{~S}$ conversion and sulfur selectivity close to $100 \%$. The results of in situ DRIFTS characterization confirm that the addition of acetic acid can lead to the creation of extra Lewis acid sites (LAS), and the discrepancy in LAS content causes difference in catalytic activity. The results of the present work can serve as guidelines for the design of stable and efficient catalysts to circumvent the shortcomings of conventional iron-based catalysts for $\mathrm{H}_{2} \mathrm{~S}$ selective oxidation.

\section{Experimental}

\subsection{Materials}

1,4-Benzenedicarboxylic acid $\left(\mathrm{H}_{2} \mathrm{BDC}\right)$ was purchased from Sigma-Aldrich (Shanghai, China). Acetic acid (HAc), methanol, $N, N^{\prime}$-dimethylformamide (DMF), and $\mathrm{FeCl}_{3} \cdot 6 \mathrm{H}_{2} \mathrm{O}$ were purchased from Sinopharm Chemical Reagent (Shanghai, China). All the chemicals were directly used without further treatment.

\subsection{Synthesis of catalysts}

Typically, $\mathrm{H}_{2} \mathrm{BDC}\left(1.236 \mathrm{~g}\right.$ ) and $\mathrm{FeCl}_{3} \cdot 6 \mathrm{H}_{2} \mathrm{O}$ (4.05 g) were dissolved in DMF (45 mL) in a Teflon autoclave and sonicated to obtain a homogeneous solution. After that, a designated volume $(x)$ of acetic acid was added dropwise to the solution. Then the resulted mixture was subject to sonication for $10 \mathrm{~min}$, and heated in an oven at $170{ }^{\circ} \mathrm{C}$ for $24 \mathrm{~h}$. After cooling to room temperature, the solid in the form of powder was isolated by filtration and washed with a large volume of methanol. The sample obtained before vacuum activation at $100{ }^{\circ} \mathrm{C}$ is herein denoted as MIL-53(Fe)- $x \mathrm{H}$ (where $x=3,5$ and $10 \mathrm{~mL}$ ). For comparison, a sample of non-modulated material named herein as MIL-53(Fe) was also synthesized following the above procedures but without adding HAc.

\subsection{Characterization}

The morphologies and elemental distribution of catalysts were acquired on an S-4800 Hitachi scanning electron microscope (SEM) equipped with an energy-dispersive X-ray spectrometer (EDX). X-ray diffraction (XRD) analysis was conducted on an X'Pert3 Powder diffractometer using $\mathrm{Cu} K_{\alpha}$ radiation at $45 \mathrm{kV}$ and $40 \mathrm{~mA}$. Thermogravimetric (TG) analysis and differential scanning calorimetry (DSC) were performed on a NETZHCS STA2500 Regulus TG/DSC system under flowing air with a ramping rate of $5{ }^{\circ} \mathrm{C} \cdot \mathrm{min}^{-1}$. Fourier transformed infrared (FT-IR) spectra were acquired using a Nicolet-6700 spectrometer. Raman spectra were collected on a Renishaw Raman spectrometer furnished with a laser beam of $\lambda=325 \mathrm{~nm}$. The $\mathrm{N}_{2}$ adsorption-desorption isotherms were obtained over an U.S. Micromeritics 3Flex analyzer at $-196^{\circ} \mathrm{C}$. X-ray photoelectron spectroscopy (XPS) measurements were conducted on a Thermo ESCALAB 250 spectrometer. The Fe contents were examined on an Optima 8000 Inductively Coupled Plasma Emission spectrometer (ICP-OES). The surface acid properties of samples were studied by in situ DRIFTS technique using pyridine as probe. Before the adsorption of pyridine, the MIL-53(Fe)- $x \mathrm{H}$ samples were heated in helium atmosphere $\left(150{ }^{\circ} \mathrm{C}, 3 \mathrm{~h}\right)$ to exclude the influence of adsorbed impurities.

\subsection{Desulfurization measurement}

The selective oxidation of $\mathrm{H}_{2} \mathrm{~S}$ to sulfur over MIL-53(Fe)- $x \mathrm{H}$ was conducted in a fixed-bed reactor in the temperature range of $100-190^{\circ} \mathrm{C}$ under atmospheric pressure. The catalyst $(0.2 \mathrm{~g})$ was loaded in the central of the reactor and a mixture gas containing $2500 \mathrm{ppm} \mathrm{O}_{2}, 5000$ ppm $\mathrm{H}_{2} \mathrm{~S}$ and balance $\mathrm{N}_{2}$ was introduced into the reactor at a total flow rate of $10 \mathrm{~mL} \mathrm{~min}^{-1}$. During desulfurization, the effluent gases (containing $\mathrm{SO}_{2}$ and/or $\mathrm{H}_{2} \mathrm{~S}$ ) were on-line analyzed by GC9720 furnished with a TCD. A condenser was located under the reactor to trap sulfur in the outlet. Instantaneous $\mathrm{H}_{2} \mathrm{~S}$ conversion (\%), sulfur selectivity (\%) and sulfur yield (\%) are defined as follows:

$$
\begin{aligned}
& \mathrm{H}_{2} \mathrm{~S} \text { conversion }=\left(\left[\mathrm{H}_{2} \mathrm{~S}\right]_{\text {in }}-\left[\mathrm{H}_{2} \mathrm{~S}\right]_{\text {out }}\right) /\left[\mathrm{H}_{2} \mathrm{~S}\right]_{\text {in }} \times 100 \\
& \text { Sulfur selectivity }= \\
& \left(\left[\mathrm{H}_{2} \mathrm{~S}\right]_{\text {in }}-\left[\mathrm{H}_{2} \mathrm{~S}\right]_{\text {out }}-\left[\mathrm{SO}_{2}\right]_{\text {out }}\right) /\left(\left[\mathrm{H}_{2} \mathrm{~S}\right]_{\text {in }}-\left[\mathrm{H}_{2} \mathrm{~S}\right]_{\text {out }}\right) \times 100
\end{aligned}
$$

Sulfur yield $=\left[\mathrm{H}_{2} \mathrm{~S}\right.$ conversion $] \times[$ Sulfur selectivity $] \times 100$

\section{Results and discussion}

\subsection{Structure characterization}

The schematic of MIL-53(Fe)- $x \mathrm{H}$ synthesis via acetic acid 
coordination modulation is displayed in Fig. 1A. The SEM image of MIL-53(Fe) displays particles of bulky irregular morphology (Fig. 1B). The addition of HAc obviously has an effect on the morphology of MIL-53(Fe). The MIL-53(Fe)-3H sample is composed of uniform hexagonal spindle-shape crystals with sharp ends, which are ca. $15 \mu \mathrm{m}$ in length and $3 \mu \mathrm{m}$ in width (Fig. 1C). As for MIL-53(Fe)-5H, the sharp ends disappear, and the average particle length is $12 \mu \mathrm{m}$ (Fig. 1D). When the added amount of HAc was $10 \mathrm{~mL}$, the MIL-53(Fe)-10H is in the form of short hexagonal prisms 8.5 and $5.0 \mu \mathrm{m}$ in average size (Fig. 1E). It is apparent that the addition of HAc in the synthesis of MIL-53(Fe) could strongly modulate the growth of MIL-53(Fe) crystals, making size and morphology control feasible.

The structures of MIL-53(Fe) and MIL-53(Fe)- $x \mathrm{H}$ before vacuum treatment at $100{ }^{\circ} \mathrm{C}$ were studied by X-ray powder diffraction (XRD). As shown in Fig. 2, the XRD pattern of MIL-53(Fe) matches well with that of the simulated one [24]. At low HAc addition, MIL-53(Fe)-3H displays main peaks at $2 \theta$ of $9.2^{\circ}, 10.6^{\circ}, 12.6^{\circ}, 17.6^{\circ}$, and $25.4^{\circ}$, in consistent with those of MIL-53(Fe) [25]. Compared with MIL-53(Fe), MIL-53(Fe)-3H shows no obvious shift in peak position, only that the peak at $10.6^{\circ}$ of the latter is slightly higher in intensity. The slight increase of peak intensity is plausibly due to a change of crystal growth direction under the influence of HAc, in agreement with the SEM results (Figs. 1B and 1C)) [26,27]. However, a higher amount of HAc would significantly interfere the crystal growth of MIL-53(Fe). The MIL-53(Fe)-5H and MIL-53(Fe)-10H samples show diffraction patterns that are distinctly different from that of MIL-53(Fe). The $10.6^{\circ}$ and $9.7^{\circ}$ peaks of MIL-53(Fe)-5H and MIL-53(Fe)-10H are relatively higher in intensity in comparison with those of MIL-53(Fe), respectively, while the $12.6^{\circ}$ peaks weaker. The phenomena can be related to the fact that $\mathrm{HAc}$ is with carboxylate group similar to that of $\mathrm{H}_{2} \mathrm{BDC}$, and both $\mathrm{HAc}$ and $\mathrm{H}_{2} \mathrm{BDC}$ can coordinate with Fe-oxo clusters

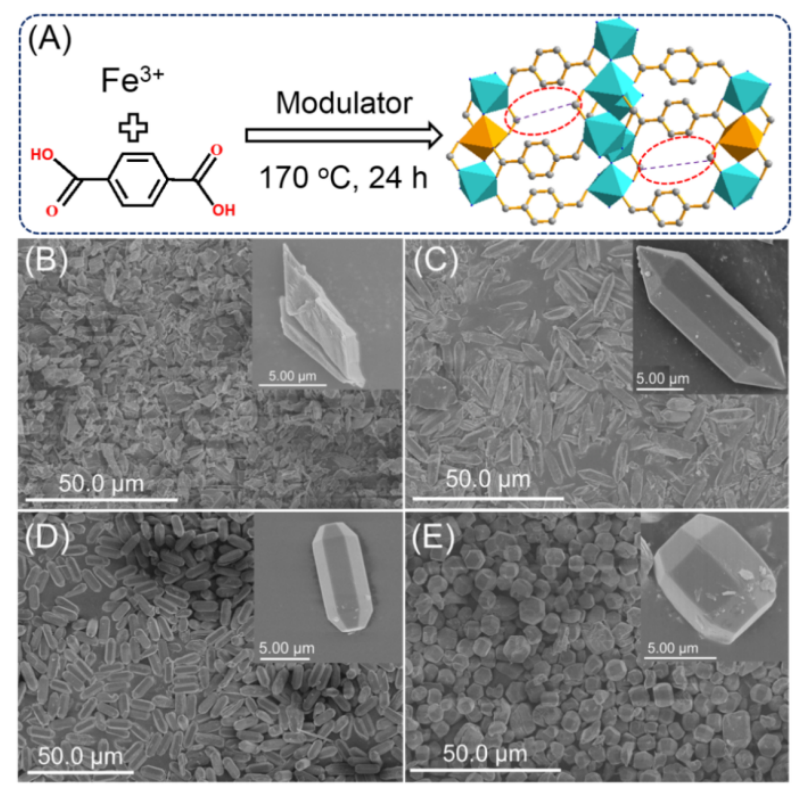

Fig. 1. (A) Schematic of MIL-53(Fe)- $x \mathrm{H}$ preparation (Gray, C; Blue, O; Aqua, $\mathrm{Fe}^{3+}$; Light Orange, $\mathrm{Fe}^{3+}$ Lewis acid sites; Purple dotted line, missing linker defects); SEM images of (B) MIL-53(Fe), (C) MIL-53(Fe)-3H, (D) MIL-53(Fe)-5H, and (E) MIL-53(Fe)-10H.

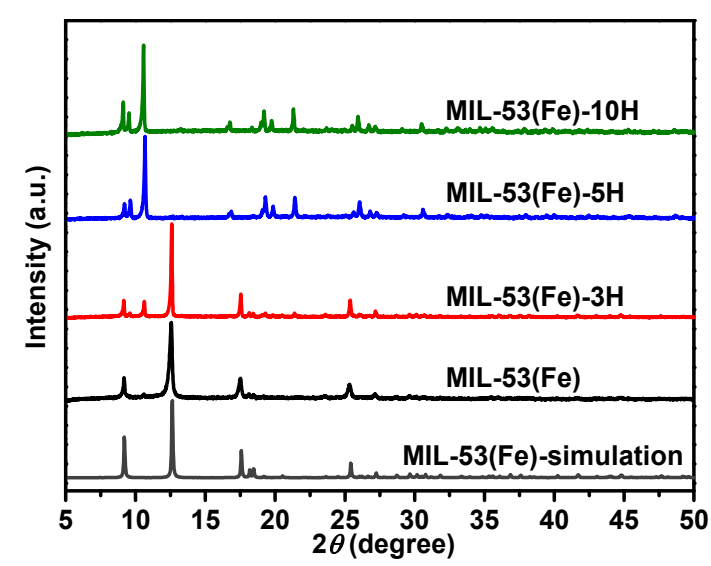

Fig. 2. XRD patterns of MIL-53(Fe) and MIL-53(Fe)- $x$ H (before vacuum treatment at $100^{\circ} \mathrm{C}$ ).

[28-30]. The $\mathrm{pKa}$ for $\mathrm{H}_{2} \mathrm{BDC}$ and HAc linkers is 3.51 and 4.76, respectively, and the competition and exchange of the two would induce structural defects [31,32]. Similar phenomena were reported in the synthesis of other MOFs when HAc was used as modulator [29]. Due to the labile and volatile property of HAc (b.p. $=118{ }^{\circ} \mathrm{C}$ ), it is possible to expose the Fe sites by having the acetate groups removed during vacuum treatment [31].

The XRD patterns of MIL-53(Fe) and MIL-53(Fe)- $x \mathrm{H}$ after vacuum treatment at $100{ }^{\circ} \mathrm{C}$ are shown in Fig. S1. It is found that the patterns of MIL-53(Fe) recorded before and after vacuum treatment are almost the same, but those of MIL-53(Fe)- $x \mathrm{H}$ are significantly different in terms of relative peak intensity. After vacuum activation, the strongest peak of MIL-53(Fe) is the one at $12.6^{\circ}$, while that of MIL-53(Fe)-3H and MIL-53(Fe)-5H is the one at $9.7^{\circ}$. In the case of MIL-53(Fe)-10H, it is the peak at $10.6^{\circ}$ that is the strongest. Interestingly, there is near complete disappearance of the $9.2^{\circ}$ and $10.6^{\circ}$ peaks when comes to MIL-53(Fe)-5H. All these discrepancies can be attributed to the variation of acetate amount in the structure of MIL-53(Fe)- $x \mathrm{H}$ samples before vacuum activation.

To validate the assumption that was based on the XRD data, the samples were subject to TG-DSC analysis (Fig. 3). Two weight losses are observed over MIL-53(Fe) (Fig. 3A). The gradual loss below $343{ }^{\circ} \mathrm{C}$ is due to the desorption of guest molecules (e.g., $\mathrm{H}_{2} \mathrm{O}$ and methanol), while the major rapid one between $343^{\circ} \mathrm{C}$ and $400^{\circ} \mathrm{C}$ can be attributed to the decomposition of frameworks together with the departure of BDC ligand [33]. The remaining mass for MIL-53(Fe) is 30.4\%, revealing that the residual is largely $\mathrm{Fe}_{2} \mathrm{O}_{3}$. Despite the TG curves (Figs. 3B-3D) of MIL-53(Fe) $x \mathrm{H}$ show a trend similar to that of MIL-53(Fe), there is clear difference in the DSC profiles. It is clear that the decomposition of MIL-53(Fe)- $x \mathrm{H}$ occurs in two steps, suggesting that there are two linkers in the framework. The remaining mass for MIL-53(Fe)-3H, MIL-53(Fe)-5H and MIL-53(Fe)- $10 \mathrm{H}$ is $32.8 \%, 27.9 \%$ and $47.1 \%$ of original, respectively. The variation could be due to difference in HAc incorporation. Moreover, the heat involved in the decomposition of the samples follows the order of MIL-53(Fe) $(5.39 \mathrm{~kJ} / \mathrm{g})>$ 

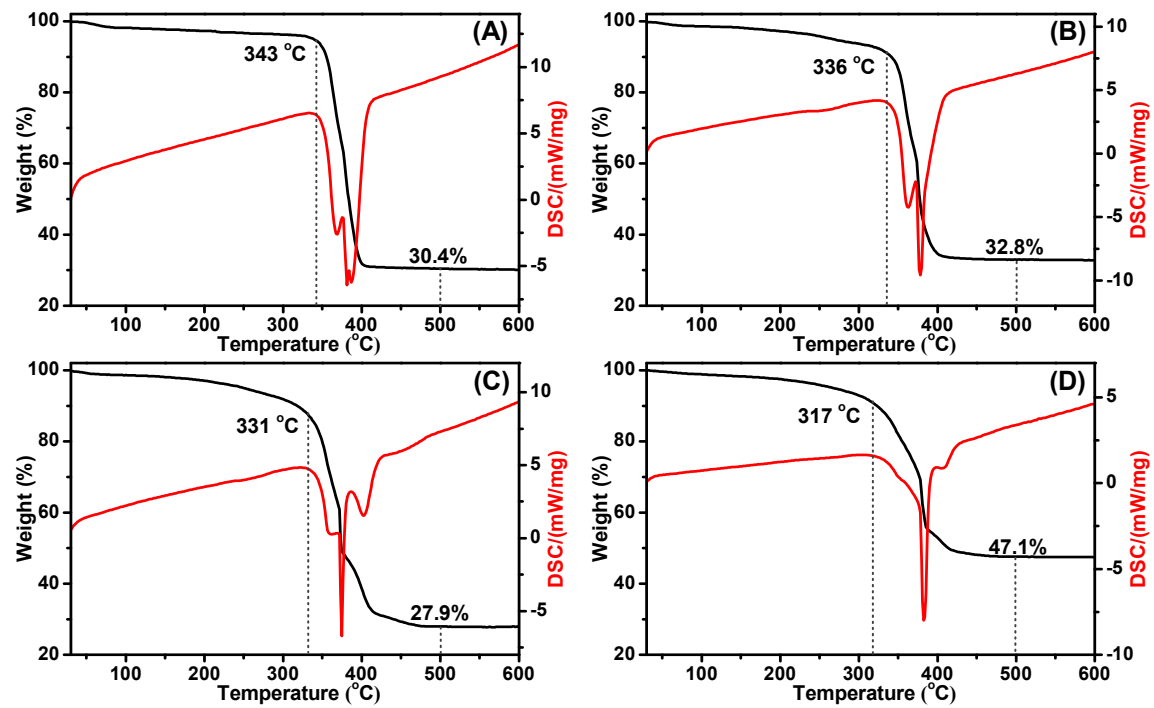

Fig. 3. DSC (red) and TG (black) curves of prepared samples: (A) MIL-53(Fe), (B) MIL-53(Fe)-3H, (C) MIL-53(Fe)-5H, and (D) MIL-53(Fe)-10H.

MIL-53(Fe)-3H (4.40 kJ/g) > MIL-53(Fe)-5H (3.18 kJ/g) > MIL-53(Fe)-10H (2.39 kJ/g). Putting the combustion heat of $\mathrm{HAc}(875.0 \mathrm{~kJ} / \mathrm{mol})$ and $\mathrm{H}_{2} \mathrm{BDC}(3225.9 \mathrm{~kJ} / \mathrm{mol})$ into consideration, a decrease of heat exchange with the increase of HAc content confirms higher HAc participation in ligand coordination with $\mathrm{Fe}^{3+}$ [34]. In order to obtain a clear estimation on the extent of HAc and $\mathrm{H}_{2} \mathrm{BDC}$ coordination in MIL-53(Fe)- $x \mathrm{H}$, we normalized the weight losses with respect to the $\mathrm{Fe}_{2} \mathrm{O}_{3}$ residue after heating to $500{ }^{\circ} \mathrm{C}$. Between $300{ }^{\circ} \mathrm{C}$ and $400{ }^{\circ} \mathrm{C}$, the weight loss of MIL-53(Fe) is in line with a BDC/Fe ratio of 1.06, indicative of $\mathrm{FeO}_{6}$ coordination with one terephthalate anion (BDC2-) (Fig. S2A). As for MIL-53(Fe)-3H, the $\mathrm{CH}_{3} \mathrm{COO}^{-} / \mathrm{Fe}$ and $\mathrm{BDC}^{2-} / \mathrm{Fe}$ ratio is 1.34 and 0.43 , respectively (Fig. S2B). The result indicates that the coordination is one $\mathrm{FeO}_{6}$ octahedral linking to $1.34 \mathrm{CH}_{3} \mathrm{COO}^{-}$and $0.43 \mathrm{BDC}^{2-}$ plausibly with a formula of $\mathrm{Fe}(\mathrm{OH})\left(\mathrm{CH}_{3} \mathrm{COO}\right)_{1.34}(\mathrm{BDC})_{0.43} \cdot x \mathrm{H}_{2} \mathrm{BDC}$. As for MIL-53(Fe)-5H and MIL-53(Fe)-10H, the $\mathrm{CH}_{3} \mathrm{COO}-/ \mathrm{Fe}$ ratio is 1.50 and 0.69 , respectively (Figs. S2C and S2D). Among MIL-53(Fe)- $x \mathrm{H}, \mathrm{MIL}-53(\mathrm{Fe})-5 \mathrm{H}$ has the highest $\mathrm{CH}_{3} \mathrm{COO}^{-} / \mathrm{Fe}$ ratio, indicating that the amount of acetate group in MIL-53(Fe)-5H is higher than that in MIL-53(Fe)-3H and
MIL-53(Fe)-10H, which is consistent with the XRD results (Fig. S1).

The FT-IR spectra of MIL-53(Fe) and MIL-53(Fe)- $x \mathrm{H}$ were collected (Fig. 4A). All of the samples exhibit the characteristic stretching vibrations of carboxylate groups in the range of $1700-1400 \mathrm{~cm}^{-1}$. The peak at $746 \mathrm{~cm}^{-1}$ is ascribed to the $\mathrm{C}-\mathrm{H}$ bending vibration of aromatic ring $[35,36]$. As for the peak at $545 \mathrm{~cm}^{-1}$, it is related to Fe-O vibration [37]. The peaks at 1543 $\mathrm{cm}^{-1}$ and $1392 \mathrm{~cm}^{-1}$ detected over MIL-53(Fe) could be assigned to the symmetric and asymmetric stretching mode of COO- group, respectively [38]. Over MIL-53(Fe)-3H, the peak at $1543 \mathrm{~cm}^{-1}$ becomes weaker and a new peak at $1587 \mathrm{~cm}^{-1}$ appears. With the amount of HAc increases from 3 to 5 or $10 \mathrm{~mL}$, the band intensity at $1587 \mathrm{~cm}^{-1}$ gradually enhances, while the peak at $1543 \mathrm{~cm}^{-1}$ disappears. The variation of the symmetric stretching vibration band of the MIL-53(Fe)- $x \mathrm{H}$ samples is ascribed to the successful coordination of HAc into the framework.

In addition, the structural information of MIL-53(Fe) and MIL-53(Fe)- $x \mathrm{H}$ was further analyzed by Raman spectroscopy. For comparison, the organic linker $\mathrm{H}_{2} \mathrm{BDC}$ was also tested un-
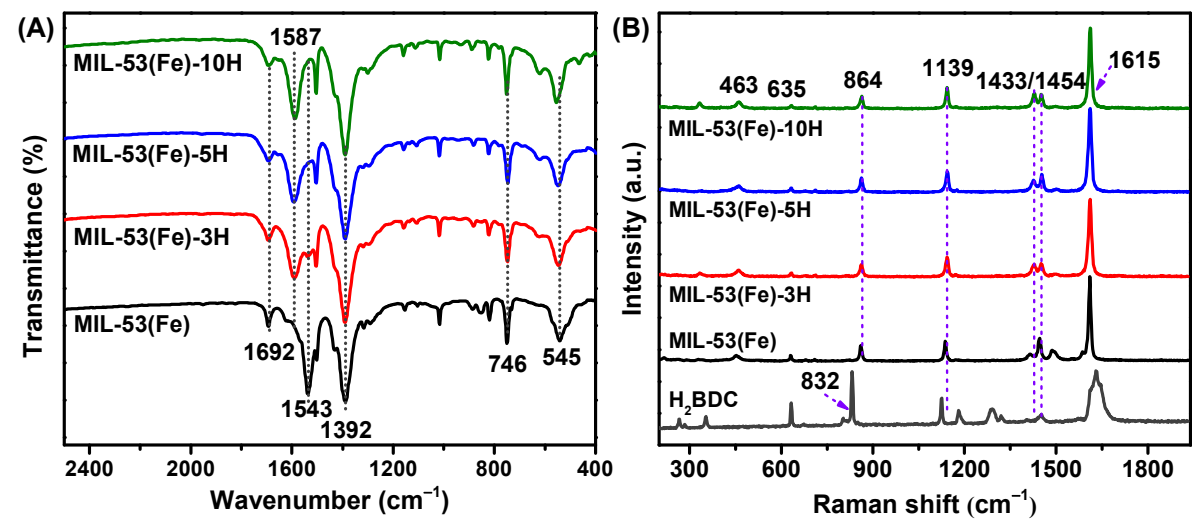

Fig. 4. (A) FT-IR spectra and (B) Raman spectra of MIL-53(Fe)-xH. 
der the same conditions. As shown in Fig. 4B, five Raman bands at $1615,1454,1125,635$, and $832 \mathrm{~cm}^{-1}$ are observed over $\mathrm{H}_{2} \mathrm{BDC}$. The first four are attributed to the out-of-plane and in-plane deformation modes of $\mathrm{C}-\mathrm{H}$ groups, while the last to the stretching vibration modes of $\mathrm{C}=0$ groups $[39,40]$. For the MIL-53(Fe) obtained by self-assembly of $\mathrm{H}_{2} \mathrm{BDC}$ and $\mathrm{Fe}$ ions, the $\mathrm{C}=0$ peak of $\mathrm{H}_{2} \mathrm{BDC}$ at $832 \mathrm{~cm}^{-1}$ disappears and a new peak at $864 \mathrm{~cm}^{-1}$ appears, which is due to $\mathrm{C}-\mathrm{O}-\mathrm{Fe}$ stretching of $\mathrm{FeO}_{6}$ octahedral, revealing the formation of $\mathrm{C}-\mathrm{O}-\mathrm{Fe}$ coordination. In addition, two new bands appear at $463 \mathrm{~cm}^{-1}$ and $1433 \mathrm{~cm}^{-1}$. The former is attributed to network binding modes and lattice vibrations, while the latter to stretching modes of carboxylate groups (-0OCC $6 \mathrm{H}_{4} \mathrm{COO}-$ and/or $\left.\mathrm{CH}_{3} \mathrm{COO}-\right)$ [41]. It is worth noting that the intensity of the $1433 \mathrm{~cm}^{-1}$ band increases with rising HAc content. Zhang et al. proposed that the "I $1433 / \mathrm{I}_{1615}$ " intensity ratios can be used to analyze the variation trend of carboxyl groups [42]. It is observed that the increase of $\mathrm{I}_{1433} / \mathrm{I}_{1615}$ ratios follows the order of MIL-53(Fe) (0.09) < MIL-53(Fe)-5H (0.15) < MIL-53(Fe)-3H (0.16) < MIL-53(Fe)-10H (0.22). Compared to MIL-53(Fe), all the MIL-53(Fe)- $x \mathrm{H}$ show higher I1433/I1615 ratio, with MIL-53(Fe)-5H being the least obvious. It is envisaged that the acetate groups could be readily removed upon vacuum activation, breaking the $\mathrm{C}-\mathrm{O}-\mathrm{Fe}$ coordination and leaving behind exposed Fe sites. These results are consistent with the deduction of XRD and TG-DSC analysis. ICP-OES results shown in Table S1 further indicate that the introduction of HAc increases the Fe content of MIL-53(Fe). In addition, the $\mathrm{N}_{2}$ adsorption-desorption isotherms of MIL-53(Fe) and MIL-53(Fe)- $x \mathrm{H}$ all show a type IV curve with H3-type hysteresis loops (Fig. S3). It is worth noting that the specific surface areas of these four materials $\left(4.1,6.5,5.2\right.$, and $5.3 \mathrm{~m}^{2} / \mathrm{g}$, respectively) are much smaller than that of other reported Fe-MOFs, plausibly due to the breathing effect of MIL-53(Fe) [43].

XPS analysis was conducted to clarify the chemical state of

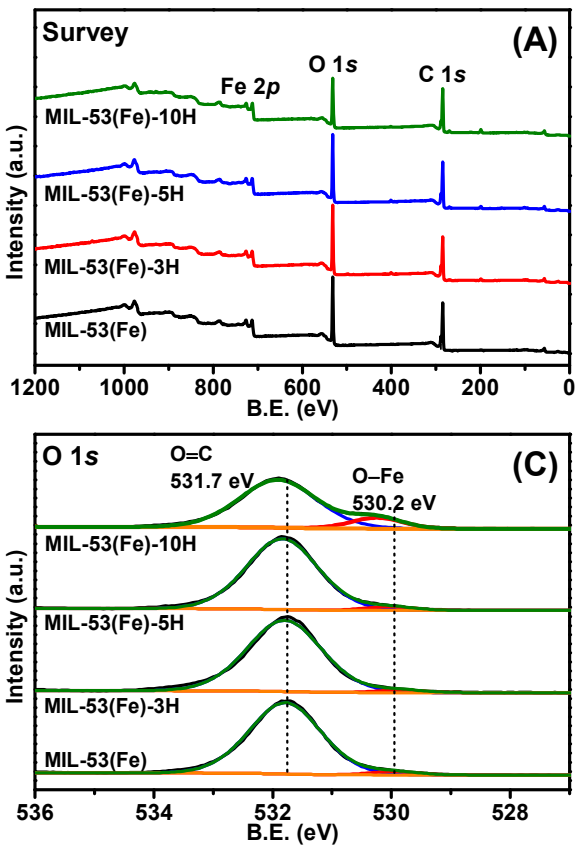

elements. In the XPS survey scans of MIL-53(Fe) and MIL-53(Fe)- $x \mathrm{H}$, signals of $\mathrm{Fe}, \mathrm{C}$ and $\mathrm{O}$ elements are observed (Fig. 5A). The $\mathrm{C} 1 \mathrm{~s}$ spectra can be fitted into three peaks at ca. 288.6, 285.9 and $284.6 \mathrm{eV}$, which could be ascribed to $\mathrm{C}=0$, C-H, and phenyl, respectively (Fig. 5B) [44]. It is noted that the intensity of the $285.9 \mathrm{eV}$ peaks increases with the rise of HAc content, mainly because of the increased coordination of HAc with Fe. For the $01 s$ spectra, the two deconvoluted peaks at $530.2 \mathrm{eV}$ and $531.7 \mathrm{eV}$ can be ascribed to $\mathrm{Fe}-\mathrm{O}$ and $\mathrm{C}=\mathrm{O}$ (Fig. 5C) $[45,46]$. It is found that with the increase of HAc content, the $\mathrm{Fe}-\mathrm{O}$ peak also shows an increasing trend, reflecting that the introduction of HAc facilitates the formation of $\mathrm{Fe}-\mathrm{O}$ sites. As presented in Fig. 5D, the peaks at $712.3 \mathrm{eV}$ and $725.6 \mathrm{eV}$ are assigned to $\mathrm{Fe} 2 p_{3 / 2}$ and $\mathrm{Fe} 2 p_{1 / 2}$, while the peak at $717.7 \mathrm{eV}$ to satellite signal of $\mathrm{Fe}^{3+}$ peak $[47,48]$. These results confirm that the Fe species in MIL-53(Fe) basically exists in the form of $\mathrm{Fe}^{3+}$. With the increase of HAc content from 3 to $10 \mathrm{~mL}$, the position of Fe $2 p_{3 / 2}$ peaks slightly shifts to lower binding energies, suggesting that the presence of HAc has a slight effect on the chemical environment of iron.

\subsection{Catalytic activity}

The catalytic properties of the prepared samples toward $\mathrm{H}_{2} \mathrm{~S}$ oxidation were tested in a packed-bed reactor under atmospheric pressure at $100-190{ }^{\circ} \mathrm{C}$. As shown in Fig. $6 \mathrm{~A}$, the $\mathrm{H}_{2} \mathrm{~S}$ conversion over MIL-53(Fe) increases with rising temperature up to $160{ }^{\circ} \mathrm{C}$, and then remains almost constant when the temperature is further increased to $190{ }^{\circ} \mathrm{C}$. Compared with MIL-53(Fe), MIL-53(Fe)- $x$ H shows higher catalytic activities at lower reaction temperature. The $\mathrm{H}_{2} \mathrm{~S}$ conversion follows the order of MIL-53(Fe)-5H > MIL-53(Fe)-3H > MIL-53(Fe)-10H > MIL-53(Fe). It is noted that when the temperature is increased to $160{ }^{\circ} \mathrm{C}$, all the prepared samples can achieve $100 \% \mathrm{H}_{2} \mathrm{~S}$ conversion, which is higher than that of $\mathrm{Fe}_{2} \mathrm{O}_{3}\left(80 \% \mathrm{H}_{2} \mathrm{~S}\right.$ conver-

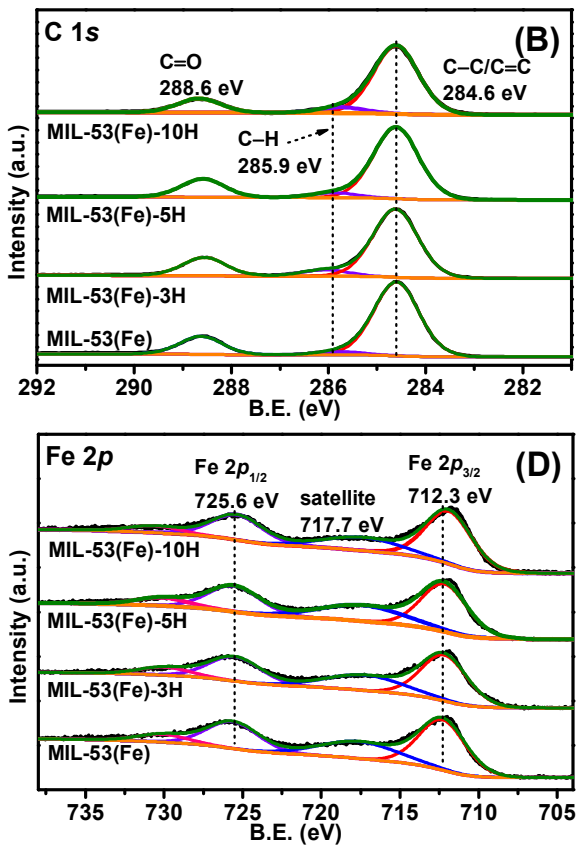

Fig. 5. XPS spectra of MIL-53(Fe)-xH: (A) survey; (B) C 1s; (C) 0 1s; and (D) Fe $2 p$. 

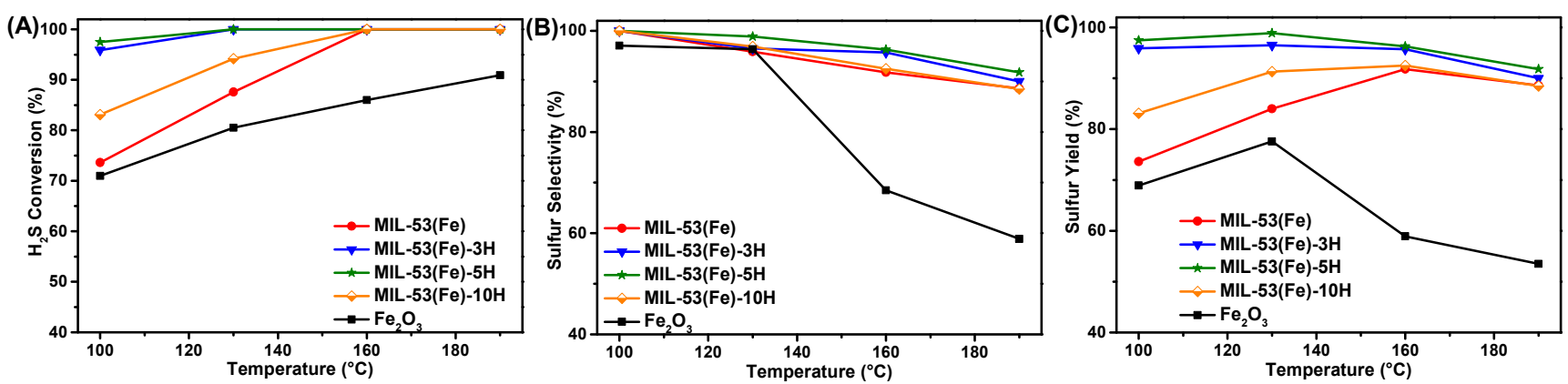

Fig. 6. Effect of reaction temperature on (A) conversion of $\mathrm{H}_{2} \mathrm{~S}$, (B) sulfur selectivity, and (C) sulfur yield over MIL-53(Fe), MIL-53(Fe)- $x \mathrm{H}$ and commercial $\mathrm{Fe}_{2} \mathrm{O}_{3}$.

sion) under the same reaction condition.

Fig. 6B shows the relationship between sulfur selectivity and reaction temperature. It can be seen that sulfur selectivity for all catalysts remains at ca. $100 \%$ below $130{ }^{\circ} \mathrm{C}$. Further increase of temperature leads to gradually decrease of sulfur selectivity. It is because side reactions are promoted at high temperatures, leading to deep oxidation of $\mathrm{H}_{2} \mathrm{~S}\left(\mathrm{H}_{2} \mathrm{~S}+3 / 2 \mathrm{O}_{2} \rightarrow\right.$ $\mathrm{SO}_{2}+\mathrm{H}_{2} \mathrm{O}$ ) or oxidation of the produced sulfur $\left(\mathrm{S}+\mathrm{O}_{2} \rightarrow \mathrm{SO}_{2}\right)$ [49]. Nevertheless, the sulfur selectivity is still higher than $89 \%$ for MIL-53(Fe) and MIL-53(Fe)- $x \mathrm{H}$ catalysts at $190{ }^{\circ} \mathrm{C}$. As for $\mathrm{Fe}_{2} \mathrm{O}_{3}$, sulfur selectivity decreases from a value of $97 \%$ at 100 ${ }^{\circ} \mathrm{C}$ to $59 \%$ at $190^{\circ} \mathrm{C}$.

The relationship between sulfur yield and reaction temperature is depicted in Fig. 6C. Over the prepared catalysts, sulfur yield initially increases with rise of reaction temperature. MIL-53(Fe) shows a maximum sulfur yield of ca. $92 \%$ at $160{ }^{\circ} \mathrm{C}$. As for MIL-53(Fe)- $x \mathrm{H}$, they show higher activity than MIL-53(Fe). Over MIL-53(Fe)-5H, maximum sulfur yield of ca. $99 \%$ is achieved at $130{ }^{\circ} \mathrm{C}$. Further increase of reaction temperature would lead to slight decrease of sulfur yield due to side reactions. All the MIL-53(Fe)- $x \mathrm{H}$ catalysts are superior to $\mathrm{Fe}_{2} \mathrm{O}_{3}$ in terms of sulfur yield. As for mass balance of sulfur, we recovered sulfur from the effluent and used catalyst and the result is in good agreement with the data of $\mathrm{H}_{2} \mathrm{~S}$ conversion and sulfur selectivity.

Fig. 7 presents the durability of MIL-53(Fe), MIL-53(Fe)-5H and commercial $\mathrm{Fe}_{2} \mathrm{O}_{3}$ at $190{ }^{\circ} \mathrm{C}$. $\mathrm{Fe}_{2} \mathrm{O}_{3}$ shows obvious deactivation, exhibiting $41 \% \mathrm{H}_{2} \mathrm{~S}$ conversion and $12 \%$ sulfur selectiv-

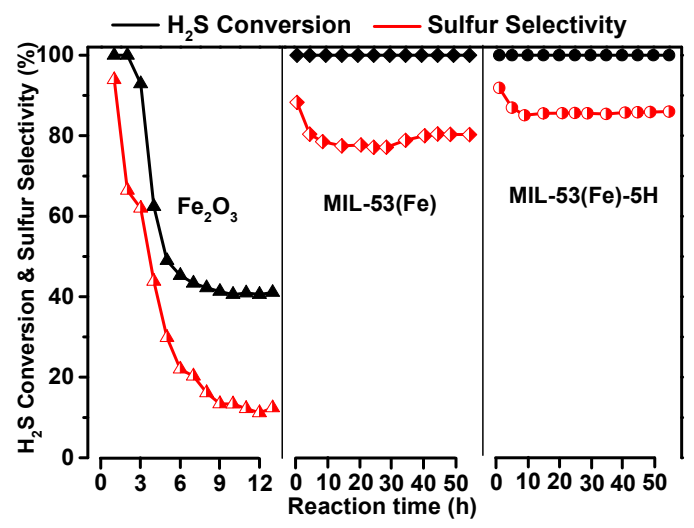

Fig. 7. Time-on-stream behavior of $\mathrm{Fe}_{2} \mathrm{O}_{3}, \mathrm{MIL}-53(\mathrm{Fe})$, and MIL-53(Fe)-5H for $\mathrm{H}_{2} \mathrm{~S}$ selective oxidation at $190^{\circ} \mathrm{C}$. ity after $13 \mathrm{~h}$ of reaction, plausibly due to the generation of inactive $\mathrm{Fe}-\mathrm{S}$ species and the deposition of sulfur [1]. In contrast, MIL-53(Fe) exhibits higher stability for desulfurization, and $\mathrm{H}_{2} \mathrm{~S}$ conversion and sulfur selectivity stabilizes at ca. $100 \%$ and $80 \%$ after $55 \mathrm{~h}$, respectively. As for MIL-53(Fe)-5H, the $\mathrm{H}_{2} \mathrm{~S}$ conversion is comparable to that of MIL-53(Fe), while sulfur selectivity (ca. 86\%) is higher than that of MIL-53(Fe) in a span of $55 \mathrm{~h}$. The results suggest that the addition of acetic acid as modulator has a profound positive effect on the catalytic performance of MOFs. Compared with other reported catalysts, MIL-53(Fe)-5H has a significant advantage in maintaining high desulfurization activity over a long reaction time (Table S2).

We further compare the structure and chemical condition of fresh and used MIL-53(Fe)-5H. As shown in Figs. S4 and S5, the XRD and FT-IR patterns of used MIL-53(Fe)-5H are similar to those of the fresh catalyst, indicating good structure integrity. Furthermore, the morphology of used MIL-53(Fe)-5H is basically the same as that of fresh sample, except for the presence of small particulates on the catalyst surface (Fig. S6). This is mainly because the reaction temperature $\left(190{ }^{\circ} \mathrm{C}\right)$ is only slightly higher than the dew point of sulfur $\left(180^{\circ} \mathrm{C}\right)$, causing incomplete sublimation of deposited sulfur. In addition, the recovered sulfur, EDX spectrum, and elemental mapping confirm the presence of sulfur in the used catalyst, albeit in trace amount (Figs. S7-S9). The XPS spectra of MIL-53(Fe)-5H before and after reaction are shown in Fig. S10. The Fe $2 p, 01 s, \mathrm{C} 1 s$ and S $2 p$ signals detected in the survey scans (Fig. S10A) confirm the presence of iron, oxygen, carbon and sulfur elements. It is noted that the Fe $2 p$ spectrum of fresh MIL-53(Fe)-5H is almost the same as that of used one, revealing a Fe valence state of +3 (Fig. S10B). Furthermore, S 2p signal can be detected over the used MIL-53(Fe)-5H (Fig. S10C). The peak at 169.1 $\mathrm{eV}$ is assignable to sulfate, whereas peaks at $164.7 \mathrm{eV}$ and 163.5 $\mathrm{eV}$ belong to sulfur [50].

\subsection{Desulfurization mechanisms}

According to literatures, $\mathrm{Fe}^{3+}$ Lewis acid sites (LAS) are active sites for selective conversion of $\mathrm{H}_{2} \mathrm{~S}$ to sulfur [50,51]. In order to understand how acetic acid acts as a regulator to affect desulfurization, the surface acidic properties of MIL-53(Fe)- $x \mathrm{H}$ were characterized by DRIFTS technique (Fig. 8). As shown in Fig. 8A, three characteristic peaks at 1070, 1043, and $1012 \mathrm{~cm}^{-1}$ 

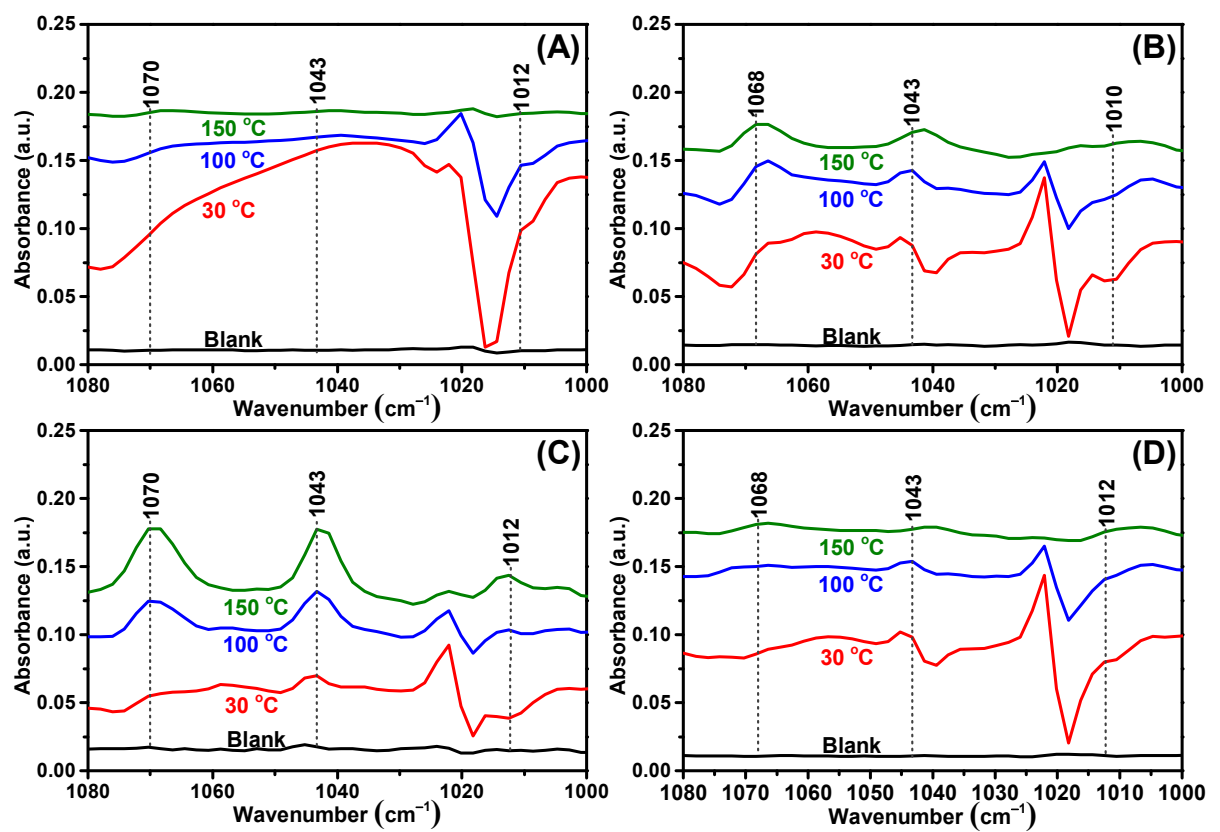

Fig. 8. Py-FT-IR spectra of (A) MIL-53(Fe), (B) MIL-53(Fe)-3H, (C) MIL-53(Fe)-5H, and (D) MIL-53(Fe)-10H after degassing at 30, 100, and $150{ }^{\circ} \mathrm{C}$.

can be observed over MIL-53(Fe), which are attributed to $v 18$, $v 12$, and $v 1$ modes of pyridine coordination with $\mathrm{Fe}^{3+}$, respectively $[52,53]$. It is worth noting that the peak intensity at 1070 $\mathrm{cm}^{-1}$ increases with the rise of degassing temperature, indicating higher pyridine coordination with $\mathrm{Fe}^{3+}$ at higher temperature. More interestingly, across the MIL-53(Fe)- $x \mathrm{H}$ catalysts

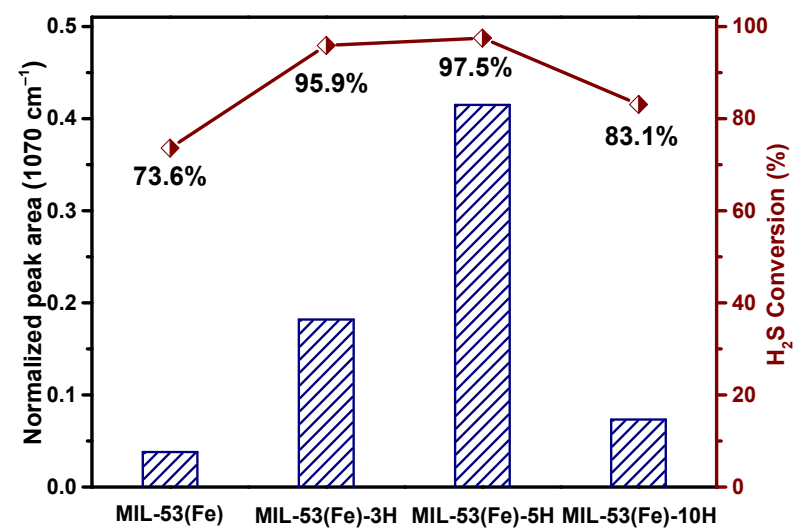

Fig. 9. Pyridine sorption peak area (at $1070 \mathrm{~cm}^{-1}$ ) and $\mathrm{H}_{2} \mathrm{~S}$ conversion over MIL-53(Fe)-xH.

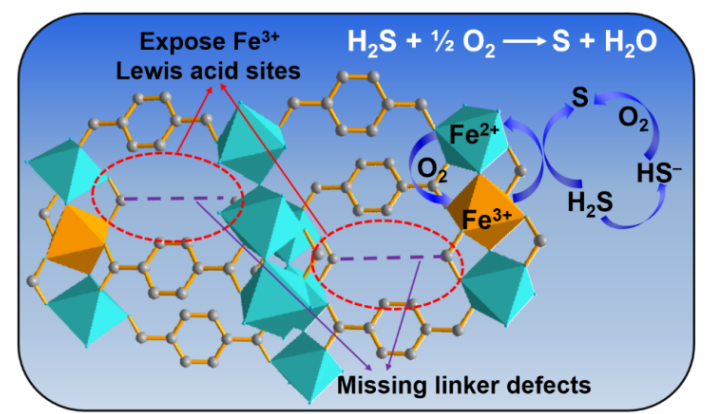

Fig. 10. Diagram of the selective conversion of $\mathrm{H}_{2} \mathrm{~S}$ to sulfur over MIL-53(Fe)- $x \mathrm{H}$. after degassing at 100 or $150{ }^{\circ} \mathrm{C}$, the intensity of peaks first increases and then decreases (Figs. 8B-8D). The results confirm that the introduction of an appropriate amount of HAc facilitates the generation of $\mathrm{Fe}^{3+}$ LAS. According to the literatures, the strength of LAS can be estimated on the basis of the peak areas of $1070 \mathrm{~cm}^{-1}$ [54]. Considering that the peak intensity after degassing at $30{ }^{\circ} \mathrm{C}$ is relatively weak, we only integrate the peaks collected after degassing at $150{ }^{\circ} \mathrm{C}$ to determine the content of medium-to-strong LAS. The $\mathrm{H}_{2} \mathrm{~S}$ conversions and peak areas of pyridine sorption over MIL-53(Fe) and MIL-53(Fe)- $x \mathrm{H}$ are displayed in Fig. 9. It is clear that the LAS content rises first and then decreases with increasing HAc content, and highest $\mathrm{Fe}^{3+}$ LAS content can be achieved over MIL-53(Fe)-5H. Over the four catalysts, $\mathrm{H}_{2} \mathrm{~S}$ conversion shows a trend similar to that of LAS amount. There is a positive correlation between LAS content and $\mathrm{H}_{2} \mathrm{~S}$ conversion, confirming that the catalytic performance of MIL-53(Fe)- $x \mathrm{H}$ for selective oxidation of $\mathrm{H}_{2} \mathrm{~S}$ is governed by LAS content.

Based on the above discussion, a plausible mechanism for catalytic $\mathrm{H}_{2} \mathrm{~S}$ selective conversion over MIL-53(Fe)- $x \mathrm{H}$ is proposed. As shown in Fig. 10, $\mathrm{H}_{2} \mathrm{~S}$ molecules diffuse on the surface of catalyst and adsorb on $\mathrm{Fe}^{3+}$ LAS. Then, the $\mathrm{H}_{2} \mathrm{~S}$ molecules are directly oxidized to $\mathrm{S}$ by $\mathrm{Fe}^{3+}$, accompanied with the reduction of $\mathrm{Fe}^{3+}$ to $\mathrm{Fe}^{2+}$. The $\mathrm{Fe}^{2+}$ ions can be re-oxidized to $\mathrm{Fe}^{3+}$ by active oxygen species for the sustention of the $\mathrm{Fe}^{2+} / \mathrm{Fe}^{3+}$ redox cycle. In addition, another possible pathway is that $\mathrm{H}_{2} \mathrm{~S}$ adsorbs and dissociates to give HS- on $\mathrm{Fe}^{3+}$ LAS, and then HSinteracts with active oxygen species to generate sulfur.

\section{Conclusions}

In summary, a series of MIL-53(Fe) with morphology evolution from irregular bulky particles to highly uniform short hexagonal prisms have been synthesized by means of acetic 
acid coordination modulation. The as-prepared MIL-53(Fe)- $x \mathrm{H}$ demonstrate outstanding performance for selective oxidation of $\mathrm{H}_{2} \mathrm{~S}$. The maximum sulfur yield over the optimal sample MIL-53(Fe)-5H at $130{ }^{\circ} \mathrm{C}$ is ca. $99 \%$, which is superior to those of conventional catalysts that are based on inorganic metal oxides. Remarkably, MIL-53(Fe)-5H also shows excellent stability (functioning for $55 \mathrm{~h}$ without deactivation). We envisage that the presented results can serve as impetus for the development of efficient desulfuration catalysts suitable for industrial applications.

\section{References}

[1] X. Zhang, G. Dou, Z. Wang, L. Li, Y. Wang, H. Wang, Z. Hao, J. Hazard. Mater., 2013, 260, 104-111.

[2] X. Zhang, Y. Tang, N. Qiao, Y. Li, S. Qu, Z. Hao, Appl. Catal. B, 2015, 176-177, 130-138.

[3] X. Zhang, Z. Wang, Y. Tang, N. Qiao, Y. Li, S. Qu, Z. Hao, Catal. Sci. Technol, 2015, 5, 4991-4999.

[4] F. Zhang, X. Zhang, Z. Hao, G. Jiang, H. Yang, S. Qu, J. Hazard. Mater., 2018, 342, 749-757.

[5] L. Shen, G. Wang, X. Zheng, Y. Cao, Y. Guo, K. Lin, L. Jiang, Chin. J. Catal., 2017, 38, 1373-1381.

[6] G. Lei, Y. Cao, W. Zhao, Z. Dai, L. Shen, Y. Xiao, L. Jiang, ACS Sustain. Chem. Eng., 2019, 7, 4941-4950.

[7] X. Zheng, Y. Li, L. Zhang, L. Shen, Y. Xiao, Y. Zhang, C. Au, L. Jiang, Appl. Catal. B, 2019, 252, 98-110.

[8] R. Sanchis, J. Cecilia, M. Soriano, M. Vázquez, A. Dejoz, J. L. Nieto, E. R. Castellón, B. Solsona, Chem. Eng. J., 2018, 334, 1159-1168.

[9] X. Zhang, Y. Tang, S. Qu, J. Da, Z. Hao, ACS Catal., 2015, 5, 1053-1067.

[10] J. Mi, X. Chen, Q. Zhang, Y. Zheng, Y. Xiao, F. Liu, C. Au, L. Jiang, Chem. Commun., 2019, 55, 9375-9378.

[11] X. Yao, J. Xu, Z. Hong, G. Li, X. Wang, F. Lu, W. Wang, H. Liu, C. Liang, Z. Lin, J. Phys. Chem. C, 2018, 122, 3263-3272.

[12] K. V. Bineesh, D. K. Kim, D. W. Kim, H. J. Cho, D. W. Park, Energy Environ. Sci., 2010, 3, 302-310.

[13] D. D. E. Koyuncu, S. Yasyerli, Ind. Eng. Chem. Res., 2009, 48, 5223-5229.

[14] H. M. Tasdemir, S. Yasyerli, N. Yasyerli, Int. J. Hydrogen Energy, 2015, 40, 9989-10001.
[15] A. V. Neimark, L. I. Kheifets, V. B. Fenelonov, Ind. Eng. Chem. Prod. Res. Dev., 1981, 20, 439-450.

[16] L. Chen, R. Luque, Y. Li, Chem. Soc. Rev., 2017, 46, 4614-4630.

[17] X. Qiu, W. Zhong, C. Bai, Y. Li, J. Am. Chem. Soc., 2016, 138, 1138-1141.

[18] P. Tan, G. Li, R. Fang, L. Chen, R. Luque, Y. Li, ACS Catal., 2017, 7, 2948-2955.

[19] G. Yilmaz, K. M. Yam, C. Zhang, H. J. Fan, G. W. Ho, Adv. Mater., 2017, 29, 1606814/1-1606814/8.

[20] G. Yilmaz, C. F. Tan, Y. F. Lim, G. W. Ho, Adv. Energy Mater., 2019, 9, 1802983/1-1802983/11.

[21] A. Kirchon, L. Feng, H. F. Drake, E. A. Joseph, H. Zhou, Chem. Soc. Rev., 2018, 47, 8611-8638.

[22] T. Deng, G. Xu, Y. Fu, Chin. J. Catal., 2020, 41, 404-414.

[23] Q. Chen, S. Li, H. Xu, G. Wang, Y. Qu, P. Zhu, D. Wang, Chin. J. Catal., 2020, 41, 514-523.

[24] P. Horcajada, C. Serre, G. Maurin, N. A. Ramsahye, F. Balas, M. Vallet-Regí, M. Sebban, F. Taulelle, G. Férey, J. Am. Chem. Soc., 2008, 130, 6774-6780.

[25] W. Dong, X. Liu, W. Shi, Y. Huang, RSC Adv., 2015, 5, 17451-17457.

[26] M. Ghorbanloo, V. Safarifard, A. Morsali, New J. Chem., 2017, 41, 3957-3965.

[27] Y. Zhao, Q. Zhang, Y. Li, R. Zhang, G. Lu, ACS Appl. Mater. Interfaces, 2017, 9, 15079-15085.

[28] F. Vermoortele, B. Bueken, G. Le Bars, B. Van de Voorde, M. Vandichel, K. Houthoofd, A. Vimont, M. Daturi, M. Waroquier, V. Van Speybroeck, J. Am. Chem. Soc., 2013, 135, 11465-11468.

[29] M. H. Pham, G. T. Vuong, A. T. Vu, T. O. Do, Langmuir, 2011, 27, 15261-15267.

[30] H. Guo, Y. Zhu, S. Wang, S. Su, L. Zhou, H. Zhang, Chem. Mater., 2012, 24, 444-450.

[31] G. Cai, H. L. Jiang, Angew. Chem. Int. Ed., 2017, 56, 563-567.

[32] T. Zhao, M. Dong, L. Yang, Y. Liu, Catalysts, 2018, 8, 394/1-394/8.

[33] D. Yu, M. Wu, Q. Hu, L. Wang, C. Lv, L. Zhang, J. Hazard. Mater., 2019, 367, 456-464.

[34] F. Evans, H. Skinner, Trans. Faraday Soc., 1959, 55, 260-261.

[35] X. Zheng, L. Shen, X. Chen, X. Zheng, C. Au, L. Jiang, Inorg. Chem., 2018, 57, 10081-10089.

[36] R. Liang, Z. Liang, F. Chen, D. Xie, Y. Wu, X. Wang, G. Yan, L. Wu, Chin. J. Catal., 2020, 41, 188-199.

\section{Graphical Abstract}

Chin. J. Catal., 2021, 42: 279-287 doi: 10.1016/S1872-2067(20)63625-7

\section{Morphology evolution of acetic acid-modulated MIL-53(Fe) for efficient selective oxidation of $\mathrm{H}_{2} \mathrm{~S}$}

Xiaoxiao Zheng, Sihui Qi, Yanning Cao, Lijuan Shen *, Chaktong Au, Lilong Jiang *

Fuzhou University

Using acetic acid coordination modulation, a series of MIL-53(Fe) with morphology evoluting from irregular bulky particles to highly uniform short hexagonal prisms were synthesized and applied for $\mathrm{H}_{2} \mathrm{~S}$ selective oxidation.

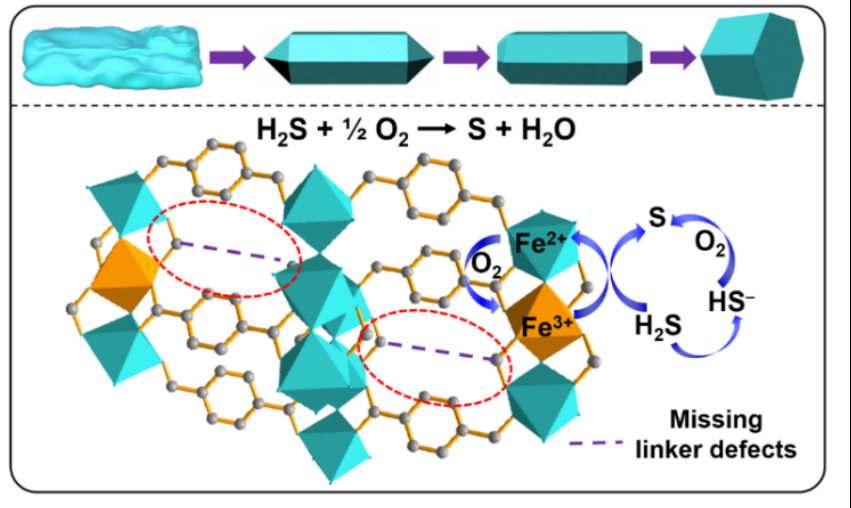


[37] G. Song, Z. Wang, L. Wang, G. Li, M. Huang, F. Yin, Chin. J. Catal., 2014, 35, 185-195.

[38] L. Ai, L. Li, C. Zhang, J. Fu, J. Jiang, Chem. Eur. J., 2013, 19, 15105-15108.

[39] L. Zhang, Y. H. Hu, Mater. Sci. Eng. B, 2011, 176, 573-578.

[40] S. Bordiga, C. Lamberti, G. Ricchiardi, L. Regli, F. Bonino, A. Damin, K. P. Lillerud, M. Bjorgen, A. Zecchina, Chem. Commun., 2004, 2300-2301.

[41] X. Li, L. Lachmanski, S. Safi, S. Sene, C. Serre, J. Grenèche, J. Zhang, R. Gref, Sci. Rep., 2017, 7, 13142/1-13142/11.

[42] Y. Hu, L. Zhang, Phys. Rev. B, 2010, 81, 174103/1-174103/5.

[43] T. Devic, P. Horcajada, C. Serre, F. Salles, G. Maurin, B. Moulin, D. Heurtaux, G. Clet, A. Vimont, J. Grenèche, B. Ouay, F. Moreau, E. Magnier, Y. Filinchuk, J. Marrot, J. Lavalley, M. Daturi, G. Férey, J. Am. Chem. Soc., 2010, 132, 1127-1136.

[44] X. Liu, Y. Zhou, J. Zhang, L. Tang, L. Luo, G. Zeng, ACS Appl. Mater. Interfaces, 2017, 9, 20255-20275.

[45] P. Wang, H. Sun, X. Quan, S. Chen, J. Hazard. Mater., 2016, 301, 512-521.

[46] H. Chen, Y. Liu, T. Cai, W. Dong, L. Tang, X. Xia, L. Wang, T. Li, ACS
Appl. Mater. Interfaces, 2019, 11, 28791-28800.

[47] F. Zhang, Y. Jin, J. Shi, Y. Zhong, W. Zhu, M. S. El-Shall, Chem. Eng. J., 2015, 269, 236-244

[48] R. Liang, F. Jing, L. Shen, N. Qin, L. Wu, J. Hazard. Mater., 2015, 287, 364-372.

[49] L. Shen, G. Lei, Y. Fang, Y. Cao, X. Wang, L. Jiang, Chem. Commun., 2018, 54, 2475-2478.

[50] X. Zheng, L. Zhang, Z. Fan, Y. Cao, L. Shen, C. Au, L. Jiang, Chem. Eng. J., 2019, 374, 793-801.

[51] E. K. Lee, K. D. Jung, O. S. Joo, Y. G. Shul, Appl. Catal. A, 2005, 284, $1-4$.

[52] A. Dhakshinamoorthy, M. Alvaro, P. Horcajada, E. Gibson, M. Vishnuvarthan, A. Vimont, J. Grenèche, C. Serre, M. Daturi, H. Garcia, ACS Catal., 2012, 2, 2060-2065.

[53] H. Leclerc, A. Vimont, J. C. Lavalley, M. Daturi, A. D. Wiersum, P. L. Llwellyn, P. Horcajada, G. Ferey, C. Serre, Phys. Chem. Chem. Phys., 2011, 13, 11748-11756.

[54] C. Volkringer, H. Leclerc, J. Lavalley, T. Loiseau, G. Férey, M. Daturi, A. Vimont, J. Phys. Chem. C, 2012, 116, 5710-5719.

\title{
乙酸调控MIL-53(Fe)的形貌演变及其高效选择性氧化 $\mathrm{H}_{2} \mathrm{~S}$ 性能
}

\author{
郑笑笑, 齐思慧, 曹彦宁, 沈丽娟*, 区泽棠, 江莉龙 ${ }^{*}$ \\ 福州大学化肥催化剂国家工程研究中心, 福建福州 350002
}

摘要: 硫化氢 $\left(\mathrm{H}_{2} \mathrm{~S}\right)$ 广泛存在于以煤、石油和天然气等为原料的化工生产过程中, 不仅腐蚀管道和设备, 而且还会对健康和 环境造成危害. 因此, 高效脱除 $\mathrm{H}_{2} \mathrm{~S}$ 已成为工业废气减排的重点. 在各种方法中, $\mathrm{H}_{2} \mathrm{~S}$ 选择性氧化技术 $\left(\mathrm{H}_{2} \mathrm{~S}+(1 / 2) \mathrm{O}_{2} \rightarrow\right.$ $\left.(1 / n) \mathrm{S}_{n}+\mathrm{H}_{2} \mathrm{O}\right)$ 由于具有设备需求低、反应不受热力学平衡限制、理论转化率可达 $100 \%$ 等优点展现出了巨大的应用前景. 实 现这一过程的关键在于发展高效稳定的催化剂. 作为一类新兴的多孔材料, 金属-有机骨架材料(MOFs)由于其独特的结构 和性质吸引了广泛的研究兴趣. 与传统的脱硫材料相比, MOFs的优势主要体现在：1) 高度分散的金属原子可作为催化活 性中心; 2) 超高比表面积和规则的孔结构有利于反应物与活性位点之间的接触; 3) 结构可调变性高, 通过在合成过程中有 目的地引入配体或调控剂可产生额外的活性位点, 满足特定催化的需求. 基于以上特点可知, MOFs是一类有潜力的催化 剂, 但目前将其应用于 $\mathrm{H}_{2} \mathrm{~S}$ 选择性氧化领域的研究尚处于起步阶段.

本文以典型的铁基MOFs MIL-53(Fe)为研究对象, 在制备MIL-53(Fe)过程中添加乙酸(HAc)作为调控剂, 通过控制HAc 的量, 得到一系列具有不同形貌的MIL-53( Fe)- $x \mathrm{H}$ 样品, 并将其应用于 $\mathrm{H}_{2} \mathrm{~S}$ 选择性氧化反应. SEM结果表明, 在MIL-53( $\mathrm{Fe}$ )的 合成过程中引入乙酸可以显著影响样品的形貌和尺寸. 活化前后样品的XRD结果表明, HAc 具有与对苯二甲酸 $\left(\mathrm{H}_{2} \mathrm{BDC}\right)$ 相 似羧基基团, 二者均可与 $\mathrm{Fe}-\mathrm{O}$ 团簇配位. 此外, TG-DSC结果证实, 随着 $\mathrm{HAc}$ 加入量的提高, 与 $\mathrm{Fe}^{3+}$ 形成配位的 $\mathrm{HAc} / \mathrm{H}_{2} \mathrm{BDC}$ 比值随之增加. FT-IR 和Raman结果进一步证明HAc成功地配位到MIL-53(Fe)的框架中, 并且参与配位的HAc可通过真空活 化移除从而暴露出 $\mathrm{Fe}^{3+}$ 不饱和位点. $\mathrm{H}_{2} \mathrm{~S}$ 选择性氧化测试表明, MIL-53( $\left.\mathrm{Fe}\right)-x \mathrm{H}$ 的脱硫活性随着 HAc含量的提高先增加然后 降低, 其中MIL-53(Fe)-5H活性最优. 此外, MIL-53( $\mathrm{Fe}$ )- $5 \mathrm{H}$ 催化剂在连续运行 55 h 后仍能保持 $100 \% \mathrm{H}_{2} \mathrm{~S}$ 转化率和 $86 \%$ 硫选择 性, 性能远优于传统的 $\mathrm{Fe}_{2} \mathrm{O}_{3}$ 催化剂. 吡啶原位红外光谱结果表明, HAc的引入可以产生额外的Lewis酸性位点(LAS), LAS 含量的不同是造成催化剂活性差异的主要原因.

关键词: 金属有机骨架材料; 硫化氢; 选择性氧化; 可控合成; 乙酸; 调控

收稿日期: 2020-03-27. 接受日期: 2020-05-11. 出版日期: 2021-02-05.

*通讯联系人. 电话/传真: (0591)83731234; 电子信箱: syhgslj@fzu.edu.cn

\#通讯联系人. 电话/传真: (0591)83731234; 电子信箱: j11@fzu.edu.cn

基金来源：国家杰出青年科学基金(21825801); 国家自然科学基金(21603034); 福建省自然科学基金(2017J05022).

本文的电子版全文由Elsevier出版社在ScienceDirect上出版(http://www.sciencedirect.com/science/journal/18722067). 